https://doi.org/10.48009/2_iis_2009_561-570

\title{
CHINESE AMERICAN ONLINE BANKING: MULTICULTURAL ACCEPTANCE OF INFORMATION TECHNOLOGY
}

\author{
Lloyd G. Gibson, Seton Hill University, gibson@setonhill.edu \\ Regina Ann Gibson, Gibson Research and Consulting, gibsonfamily01@comcast.net
}

\begin{abstract}
Technology acceptance research can be used to develop global strategies for e-commerce/service industries with market segments having multiple cultural identities. For banks to attract the fastgrowing Chinese American population, knowing the factors influencing Internet banking adoption is important. The survey ( $N=254$ Chinese Americans) used demographic and attitudinal factors from the Technology Acceptance Model and the Diffusion of Innovations Theory. Recommendations for online banking implementation are based on analysis supporting the significance of gender, language, and attitudinal factors.
\end{abstract}

Keywords: Technology acceptance, Internet banking, Online banking, Diffusion of innovations, Chinese Americans, Multiculturalism

\section{BACKGROUND}

This study was undertaken to assist a bank, which was focused on a Chinese American customer base, implement Internet or online banking. Development of successful consumer service marketing strategies to multicultural market segments, or populations with multiple cultures in their background [14], can be enhanced by technology acceptance studies. This study developed marketing strategies using factors that affect the technology acceptance of Chinese American consumers who claim both Chinese and American cultures. Internet or online banking allows consumers to perform banking transactions, including checking the balance in one's bank account, transferring funds between accounts, and bill paying, using a computer with an Internet connection.

Marketing efforts differ for various multicultural groups, particularly for Asian Americans, the "model minority" partly because of their above-average affluence and education, as compared to other ethnic groups in the U.S. ([5]; [31]). Asian Americans are also the fastest growing segment in the United States on a percentage basis [5], yet are rarely approached despite their proximity to other American cultural groups [19]. In the Asian American population,

Volume X, No. 2, 2009 which has 29 sub-groups [23], the largest sub-group is the Chinese Americans, which accounted for more than $24 \%$ of the total Asian American population in the 2000 Census [20]. Burton [3] points out that the various characteristics of a multicultural market segment could have significant marketing implications. Within the Chinese Americans subgroup, differences in reaction to a marketing strategy can be expected based on how long ago their family members emigrated and whether or not they became citizens [31].

A 2001 Pew Internet study [26] showed that Englishspeaking Asian Americans were more likely to use the Internet and were the most active users as compared to other ethnic groups, including Caucasian Americans. The Cultural Access Group [5] also indicated that $88 \%$ of Chinese Americans have a checking account, compared to $83 \%$ of Caucasian Americans. Such financial institution involvement makes Chinese Americans good candidates for online banking since a checking account is typically required to use online banking. However, if Chinese Americans perceive themselves to be outside the financial mainstream or un-banked, they could have concerns about banking and financial decisions [21].

This study was exploratory and employed a quantitative approach to examine demographic or objective characteristics [3] and attitudinal factors suggested by technology acceptance studies. Market strategy was developed based on these factors, reflecting an ethno-consumerist cross-cultural approach which views individuals as cultural beings with regard to personality, cognition, and behavior [28]. The research questions in this study focused on (a) demographic and attitudinal factors influencing the behavior of Chinese Americans, (b) differences in factors between American-born and non-American born Chinese Americans, and (c) differences in factors between Chinese Americans who prefer English and Chinese Americans who prefer a language other than English.

\section{LITERATURE REVIEW}

The model that has been used most frequently in technology acceptance studies relating to online 
banking is the Technology Acceptance Model (TAM) [6] or some modified version of the TAM. Studies using TAM surveying consumers in the U.S. ([7]; [10]; [13]; [16]) found that age, income, and education levels to have a statistically significant effect on adoption of online banking. Younger individuals with higher incomes, and higher levels of education were more likely to adopt online banking than were their older, lower income, and less educated counterparts. These studies also found that certain attitudes or perceptions positively influence adoption of this technology, including convenience, ease of use, relative advantage, and compatibility. Hogarth et al. also found that the issues of security and privacy were important in the adoption of payment technologies in general.

Studies of online banking adoption outside the United States include those done in China by Chan and $\mathrm{Lu}$ [4], Laforet and Li [15], Shih and Fang [25], Wan, Luk, and Chow [29], and Wang, Wang, Lin, and Tang [30]. Although the findings related to attitudes in these studies were similar to those in the U.S. studies, the demographic findings were somewhat different. Age, income level, and education level did not have the same impact in the studies done in China. This disagreement could be due to national factors such as the ones described in the study performed by Brown, Hoppe, Mugera, Newman and Stander [2], including socioeconomic conditions and the extent of Internet adoption. Risk factors, primarily related to security and privacy, were important issues in all of the studies done in China.

The results from studies that have examined the demographic factors affecting online banking adoption also have demonstrated some inconsistencies. Studies done in the United States have shown that age, income, and education tend to have a statistically significant impact on online banking adoption ([7]; [10]; [13]). These studies also showed no significant relationship between gender and online banking adoption. However, Laforet and $\mathrm{Li}$ [15] showed that Mainland China online banking users were predominately male but not necessarily younger, more highly educated, nor with higher income. In Hong Kong, Wan et al. [29] showed only a slight difference in gender use of online banking, and that online banking adoption was more likely among those with moderate wealth and a moderate level of education. Other studies done in Singapore [12] and Turkey [1] found that online banking adopters are more likely to be male and younger (between 31 and 40). Because these differences may be attributable to either national or cultural differences, the demographics that affect online banking adoption by Chinese Americans are not known.

Previous studies have shown that attitudinal factors (also referred to as perceptions, characteristics, or experiences) affect online banking adoption. Four factors have most frequently demonstrated statistically significant relationships with online banking adoption: perceived ease of use (PEOU), security, convenience, and computer self-efficacy. PEOU is the user's perception that online banking is easy for him or her to use. In this context, computer self-efficacy is a user's belief in his, or her, own ability to use a computer. These factors have demonstrated statistically significant relationships in studies performed in the U.S. ([10]; [16]; [24]), Singapore [8], the United Kingdom [11], Turkey [1], and China ([4]; [15]; [30]). Other factors that have been identified in these studies are perceived usefulness, relative advantage, compatibility, and complexity (perceived ease of use).

The factors from two models, the Technology Acceptance Model (TAM) and Diffusion of Innovations Theory (DOIT), were used in the U.S. by Kolodinsky et al. [13] and Lee et al. [17]. The results of these studies indicated that certain demographic and attitudinal factors influenced online banking adoption. These factors included education, income, compatibility, and relative advantage. However, Chinese Americans were not considered as a group, and their numbers were so small that they were included as part of a larger race/ethnicity group. Thus, while the findings were statistically significant, these findings did not necessarily apply to the Chinese American segment. Despite the lack of one set of universally accepted factors related to online banking adoption, the TAM and DOIT offered a promising framework for further study. In addition to the five factors in Rogers' DOIT model, security and perceived usefulness were factors examined in the Kolodinsky et al. and Lee et al. studies. These factors are ones that were consistently shown to have some influence on the intention to adopt and the actual adoption of online banking.

\section{METHODOLOGY}

The existing multicultural marketing research is highly quantitative in its approach and therefore reflects the bias of mainstream marketing research with surveys being used as the most widely used methodological approach [3]. A quantitative methodology was also used in this study since the intent of the study was to generalize the results to a 
larger metropolitan population. The population studied was the Chinese American population in the Chicago metropolitan area, which included Cook, DuPage, Lake, and Will counties. This population consisted of 66,051 people according to the 2000 U.S. Census report. The researcher approached leaders from 16 different community groups and organizations with primarily Chinese American members, clients, volunteers, and/or employees to obtain surveys from each group. In addition, since the employees, members, volunteers, and clients of these organizations were primarily located in Cook County, additional participants were obtained from employees and customers in a suburban mall located in DuPage County.

The researcher developed a survey instrument to gather data to address the research questions outlined in the Introduction. The statements and questions included in the survey were suggested by items included on a questionnaire administered by the Survey Research Center at the University of Michigan (1999 and 2003), and adapted here with the kind permission of Dr. Jeanne M. Hogarth. The survey instrument used to collect data for this study was initially developed in English. The questions and statements used by the Survey Research Center in their survey were developed primarily from other studies where they demonstrated validity and reliability.

Previous scientific studies done in the United States that included Chinese Americans were conducted in English, either through the use of oral interviews or written questionnaires. The language used in the written survey for this study was important because $73 \%$ of the population studied was foreign-born and $88 \%$ of the same population of those five years of age or older spoke a language other than English in their home, according to the 2000 U.S. Census. These facts led to the conclusion that the written survey used in this study should be available in both English and Chinese in order to have the best chance of reaching a representative sample of this population. Thus, the English version of the survey was translated into a version printed in Traditional Chinese [9].

One of the primary objectives of this study was to determine what demographic and attitudinal factors affect online or Internet banking adoption. The dependent variable that addressed this objective was intention to use Internet banking. This study provided for multiple values based upon a 7-point Likert scale response to the question, "How likely are you to use Internet banking in the next twelve months?" The responses ranged from definitely will not to definitely will and were coded sequentially from 1 to 7 , respectively. There were 15 independent demographic variables examined in this study. The demographic variables include PC (personal computer) access, Internet access/connection/use, gender, marital status, age, income, education, birthplace, primary language, and occupation. In addition, responses to 15 attitudinal statements and their relationships to the dependent variable were examined.

One-way ANOVA was used test for relationships between the demographic variables and intent to use Internet banking, and correlation analysis followed by multiple linear regressions was used to test for relationships between the attitudinal variables and intent to use. These same analyses were used to examine the sub-groups described in the research questions.

\section{RESULTS}

There were 279 surveys collected, and the participants identified their ethnicity as Chinese American on 254 of them. A detailed breakdown of the sample is provided in Table 1. This sample, while not random, was diverse and could be considered representative of the general population.

\section{<Insert Table 1 here >}

One-way ANOVA revealed that 12 of the 15 demographic factors demonstrated statistically significant relationship with participants' intent to use Internet banking. These 12 factors, along with the statistical significance they demonstrated, are included in Table 2. The six factors related to $\mathrm{PC} /$ Internet access and uses were the most significant followed by age, education, survey language, gender, household income, and country of birth. Participants who used Internet banking in the last 12 months were the most likely to intend to use Internet banking within the next 12 months. More access to the Internet and more experience in using the Internet were also positively related to the intent to use Internet banking.

\section{<Insert Table 2 here>}

Note. The superscripts in the far right column indicate statistically significant differences between attributes from the Bonferroni procedure.

Education level and household income were both positively related to intent to use Internet banking, 
while age was inversely related. The results also showed that females and participants who completed the English version of the survey scored higher than their counterparts in their intent to use Internet banking within the next 12 months. A correlation analysis revealed that all 15 of the attitudinal statements had a statistically significant relationship with the dependent variable, intent to use. The results of this initial analysis are detailed in Table 3.

\section{<Insert Table 3 here $>$}

The differences between American born and nonAmerican born Chinese Americans in demographic and attitudinal factors that influence intent to use Internet banking were not significant. However, an analysis of the difference between the participants' responses to the English and Chinese versions of the survey revealed that age was significant in the English sub-group, but not in the Chinese sub-group. There were only minor differences in the order of significance of the demographic factors between these two sub-groups.

There were several differences between the survey language sub-groups in terms of the attitudinal statements related to intent to use Internet banking. The analysis of the responses to the Chinese version showed that 10 out of the 15 statements exhibited significance while 13 of 15 did with the English version. The statements where there were differences and the corresponding correlation results are detailed in Table 4.

\section{<Insert Table 4 here $>$}

\section{DISCUSSION}

The results revealed that 12 of the 15 demographic factors exhibited statistically significant relationships with the dependent variable, intent to use Internet banking. In addition, all 15 attitudinal statements related to the six factors demonstrated a statistically significant relationship with the dependent variable. The relationships of several of the demographic factors with intent to use Internet banking were consistent with previous studies performed in the United States. All six of the PC/Internet related factors demonstrated statistical significance, with prior use of Internet banking having the most significant influence. These findings are consistent with those in studies done in the U.S. by Lee et al.

Volume X, No. 2, 2009
[17], and Lassar et al. [16]. In both of these studies heavier computer and Internet use and a higher comfort level with technology were related to a stronger likelihood of Internet banking adoption. This was also the case in the study performed by Laforet and Li [15] in Mainland China.

The results of this study indicated that age, education, and household income all had a significant relationship with the intent to use Internet banking. A younger age group with a higher level of education and higher household income were more likely to intend to use Internet banking. These findings are consistent with those in studies done in the U.S. by Hogarth et al. [10], Kolodinsky et al. [13], and Lee et al. [17]. However, the results of this study differed from those in the study by Lassar et al. [16] that indicated that while income had a significant relationship with Internet banking adoption, age, and education did not. In addition, the study performed in China by Laforet and $\mathrm{Li}$ [15] indicated that education was not a significant factor related to Internet banking adoption.

Two results of this study that differed from previously referenced studies were (a) gender was a significant factor related to intent to use Internet banking and (b) females were more likely to intend to use Internet banking than males. Previous studies indicated that gender was either not a significant factor or males were the more likely users of Internet banking. However, a study of Australian banking consumers by Lichtenstein and Williamson [18] indicated that female Internet banking users valued convenience above other characteristics, particularly working mothers. This is consistent with the results of this study of Chinese Americans since the sample had a high percentage of working $(77 \%)$ and married (72\%) women.

Unlike previous studies, this study also examined cultural/language factors related to Internet banking use. The results related to country of birth and primary language were both mixed. While country of birth demonstrated statistical significance related to intent to use, the results were not compelling and there was no significant difference in the results between U.S. and foreign-born participants. Whereas the primary language spoken at home did not demonstrate a significant relationship with intent to use Internet banking, the language of the survey did, with several significant differences in the results for those that completed the English version as compared to the results of those that completed the Chinese version. Given the many multiple responses to the primary language question, the language (Chinese or 
English) of the survey completed by each participant was believed to be more indicative of the preferred language of the participants. In addition, the author's personal experience indicates that individuals who are comfortable completing a survey in Chinese are comfortable with the spoken Chinese language as well. However, individuals comfortable with the spoken Chinese language are not necessarily comfortable completing a survey printed in Chinese.

The findings pertaining to the attitudinal factors in this study were consistent with the theories and models developed as part of Davis' TAM and Rogers' DOIT. These factors include perceived ease of use/compatibility/complexity, perceived usefulness, perceived risk/security, perceived reliability/relative advantage, trialability, and observability. Further analysis using multiple linear regression revealed that perceived usefulness and trialability were the two most significant factors related to intent to use Internet banking. These two factors were followed by perceived reliability/relative advantage and perceived risk/security. Perceived usefulness, perceived risk/security, and perceived reliability/relative advantage have demonstrated significance in several of the studies referred to in this paper ([4]; [6]; [10]; [13]; [17]; [18]; [29]; and [30]). However, the results related to trialability have been mixed, demonstrating significance in the study by Lee et al. [17], but not in the study by Kolodinsky et al. [13].

The six attitudinal statements that were the most significant in the multiple regression analysis relate to four attitudinal factors as detailed in Table 2. The first two factors, perceived usefulness and perceived risk/security, are related to the TAM or a modified version of it. The other two factors, perceived reliability/relative advantage and trialability, are related to the model developed from DOIT. All three of the statements associated with perceived usefulness are included in these six statements supporting its use in the TAM.

The demographic characteristics of the sample used in this study were similar to those of the target population. However, the sample was not random; rather it was the result of a series of convenience samples. Because of this, general conclusions about the target Chinese American population in the Chicago area cannot be drawn. In addition, the data were subject to interpretation because of language and cultural differences. Every attempt was made to minimize these interpretational differences by using two versions of the survey instrument, Chinese and English.

\section{CONCLUSIONS AND RECOMMENDATIONS}

The results of this study indicate that offering Internet banking is important for a bank that is attempting to attract Chinese Americans as customers in the Chicago area. There was a high correlation between responses in the survey to the question, "For me to choose a bank as my primary bank, how important is it that the bank offers Internet banking?" and "How likely are you to use Internet banking in the next 12 months?" In addition, $61 \%$ of the total participants responded that they were somewhat likely to use Internet banking in the next 12 months, very likely, or definitely would. This leads to the conclusion that Internet banking is a service that may help to attract Chinese American customers.

The next question to address is how can Internet banking best be implemented in order to maximize its effect? Firstly, the target audience should be identified. In the case of this market segment, the initial focus should be on current and experienced computer and Internet users. The most likely users of Internet banking among this group include age groups up to 55 years of age with higher income $(\$ 50,000$ and over) and a college or post-graduate education. When attempting to reach these individuals, it would be important to take certain findings of this study into account.

When attempting to reach out to individuals who prefer to receive material in Chinese, age may not be a significant factor, as indicated by the results from the participants that completed the Chinese version of the survey. In addition, the population aged 55 and older should not be ignored; in particular, the group aged 55 to 64. According to the results of this study, there was not a significant difference between participants from the aged 55 to 64 group and the groups aged 18 to 24 and 45 to 54 .

When attempting to reach the higher income households, care should be taken as to what types of marketing lists are used because many households may consist of extended families where the household income consists of more than two individual incomes that can easily aggregate to more than $\$ 50,000$. In addition, do not ignore households that do not report or under report income. In the survey, the income question was the one least answered. When certain sub-groups were examined, such as those who completed the Chinese version of the survey, household income was not a significant factor. One reason for this may have been that some participants under-reported their household income. 
This would result in a larger number of lower-income participants who would be likely to intend to use Internet banking. Individuals in this population segment routinely under-report income.

The education level of potential users and customers can also be misleading. Targeting only U.S. college graduates ignores the segment of this population that have college degrees and post graduate degrees that were earned outside of the U.S. While this issue was not addressed in this study, it may be one to consider from a marketing standpoint. In addition, the results of this study showed that there was not a significant difference in responses to the intent to use Internet banking between participants that had a college or post-graduate degree and those that had completed some college, a technical school degree, or an associate's degree.

A successful implementation of Internet banking should also consider the attitudinal factors and statements that demonstrated statistical significance in this study. These factors are examined here beginning with perceived usefulness. This factor addresses the general advantages of Internet banking, including how convenient it is, and that Internet banking can help someone better manage their personal finances. This suggests that marketing literature for an Internet banking product should emphasize these characteristics. In addition, the design of the Internet program should allow for integration of all bank accounts and loans, as well as other investments, in order to make the program more convenient for the user to help the user better manage all of their personal finances. The program could also provide for rewards like cash back for each bill paid through Internet banking as a further advantage to using this product.

Secondly, successful implementation should consider trialability. According to Rogers [22], "trialability is the degree to which an innovation may be experimented with on a limited basis" (p. 16). This factor and the underlying statement in the survey had the second highest correlation with the intent to use Internet banking. This factor can be addressed in two different ways. Demonstrations could be set up in each of the bank's branch offices so that existing and prospective customers can have the opportunity to try Internet banking with a customer service representative there to assist them or answer any questions they may have. This service could also be included in the bank's marketing literature. Another approach to induce individuals to try the bank's Internet banking product is to offer some type of contest or reward for just trying the product.
The third factor to address for successfully implementing Internet banking is perceived reliability/relative advantage. The specific statement that was significant in the survey was, "Mistakes with Internet banking are more difficult to get corrected than with regular banking." This could be addressed by providing a customer service representative whose primary duty was to correct any errors that may occur. This service could also be part of the marketing literature including a toll free telephone number to call for assistance.

The final attitudinal factor that affects successfully implementing Internet banking is the issue of perceived risk/security. The specific statement that was significant in the survey was, "I worry that Internet banking is not secure enough to protect my personal financial information." This issue should be addressed in the marketing literature and on the Internet banking website including the prominent display of security safeguards with particular emphasis on the security measures that are used in this regard. While this approach cannot address everyone's concerns, the results of my study indicate that this issue deserves specific attention and emphasis. The approaches to Internet banking implementation suggested here are not solutions to all of the issues that were raised in this study, but could go a long way toward addressing ones that seem to be of particular interest or concern to the targeted population.

\section{AREAS FOR FUTURE RESEARCH}

The issue of gender differences in Internet banking adoption is one that may relate to the issue of a multicultural population. The results in this study indicate that gender had a significant influence on intent to use Internet banking and that females were more likely to intend to use it. This result differed from the results of other studies of native and single culture populations and may have its roots in the attitudes of working women and working mothers in U.S. culture seeking convenience. In any event, it deserves further study.

Overall this study provides a first look at Internet banking adoption by a Chinese American population in the United States. Many issues have arisen from the study that should be addressed in future studies. The effect of language on Internet banking adoption by Chinese Americans is one that should be further addressed. The results in this study related to language were mixed, and the significance of language related to adoption was unclear. In 
addition, language options on an Internet banking website were not studied here and could be part of a future study.

Several additional issues arose during the course of this study that should be considered for future studies. These issues include income reporting, differences in college degrees, size of households, and regional differences. The first two issues may have their roots in multiculturalism. This study suggests that there may be some issues regarding the accuracy of household incomes reported and differences in technology adoption between individuals who received their college degrees in the U.S. versus other countries. The other two areas not addressed in this study, size of household and regional differences, are ones that also bear further study.

\section{REFERENCES}

1. Akinci, S., Aksoy, S., \& Atilgan, E. (2004). Adoption of Internet banking among sophisticated consumer segments in an advanced developing country. The International Journal of Bank Marketing, 22(2/3), 212-232.

2. Brown, I., Hoppe, R., Mugera, P., Newman, P., \& Stander, A. (2004). The impact of national environment on the adoption of Internet banking: Comparing Singapore and South Africa. Journal of Global Information Management, 12(2), 1-26.

3. Burton, D. (2005). New course development in multicultural Marketing. Journal of Marketing Education, 27(2), 151-162.

4. Chan, S. \& Lu, M. (2004). Understanding Internet banking adoption and use behavior: A Hong Kong perspective. Journal of Global Information Management, 12(3), 21-43.

5. Cultural Access Group (2004). Asian American Market Report. Retrieved on February 22, 2005, from www.accesscag.com.

6. Davis, F. (1989). Perceived usefulness, perceived ease of use, and user acceptance of information technology. MIS Quarterly, 13(3), 319-340.

7. Fallows, D. (2004). The Internet and daily life. Pew Internet \& American Life. Retrieved October 11, 2005, from www.pewinternet.org

8. Gerrard, P. \& Cunningham, J. B. (2003). The diffusion of Internet banking among Singapore consumers", The International Journal of Bank Marketing, 21(1), 16-28.

9. Gibson, L. G. (2007). Research design for assessing attitudes in technology acceptance: Chinese Americans and Internet banking", Information Systems Education Journal, 5(34), 539-549.
10. Hogarth, J. M., Kolodinsky, J. M., \& Gabor, T. (2006). Consumer payment choices: Paper, plastic - or electrons? Consumer Interests Annual, 52, 1-14.

11. Howcroft, B., Hamilton, R., \& Hewer, P. (2002). Consumer attitude and the usage and adoption of home-based banking”, Marketing, 20(2/3), 111121.

12. Jaruwachirathanakul, B. \& Fink, D. (2005). Internet banking adoption strategies for a developing country: The case of Thailand, The International Journal of Bank Marketing, 15, 295-311.

13. Kolodinsky, J. M., Hogarth, J. M., \& Hilgert, M. (2004). The adoption of electronic banking technologies by U.S. consumers. The International Journal of Bank Marketing, 22(4/5), 238-259.

14. Korzenny, F. (2008). Multicultural marketing and the reasons why. Journal of Advertising Research, 48(2), 173-176.

15. Laforet, S. \& Li, X. (2005). Consumers' attitudes towards online and mobile banking in China, The International Journal of Bank Marketing, 23(5), 362-380.

16. Lassar, W., Manolis, C., \& Lassar, S. S. (2005). The relationship between consumer innovativeness, personal characteristics, and online banking adoption. The International Journal of Bank Marketing, 23(2/3), 176-199.

17. Lee, E-J., Lee, J., \& Eastwood, D. (2003). A two-step estimation of consumer adoption of technology-based service innovations. The Journal of Consumer Affairs, 37(2), 256-282.

18. Lichtenstein, S. \&Williamson, K. (2006). Understanding consumer adoption of Internet banking: An interpretive study in the Australian banking context. Journal of Electronic Commerce Research, 7(2), 50-66.

19. President's Advisory Commission on Asian Americans and Pacific Islanders (2003).Asian Americans and Pacific Islanders addressing health disparities: Opportunities for building a healthier America. Washington, DC: U.S. Government Printing Office.

20. Reeves, T. J. \& Bennett, C. (2004). We the people: Asians in the U.S. Washington, DC: U.S. Census Bureau.

21. Rhine, S.L.W. \& Greene, W. H. (2006). The determinants of being unbanked for US immigrants., 21-40. Journal of Consumer Affairs, 40, 21-40.

22. Rogers, E. M. (2003). Diffusion of innovations $\left(5^{\text {th }}\right.$ ed. $)$. New York: Free Press. 
23. Rossman, M. L. (1994). Multicultural marketing: Selling to a diverse America., New York: American Marketing Association.

24. Sarel, D. \& Marmorstein, H. (2003).Marketing online banking services: The voice of the customer. Journal of Financial Services Marketing, 8(2), 106-118. .

25. Shi, Y-Y. \& Fang, K. (2004). The use of a decomposed theory of planned behavior to study Internet banking in Taiwan. Internet Research, 14(3), 213-223.

26. Spooner, T. (2001). Asian-Americans and the Internet: The young and the connected. Pew Internet \& American Life. Retrieved October 11, 2005, from www.pewinternet.org

27. U.S. Census Bureau (2000). American fact-finder summary files, 2000. Retrieved September 11, 2006, from http://factfinder.census.gov
28. Venkatesh, A. (1995). Ethnoconsumerism: A new paradigm to study cultural and cross-cultural consumer behavior. In J. A. Costa \& G. J. Bamossy (Eds.), Marketing in a multicultural world. London: Sage.

29. Wan, W. W. N., Luk, C-L., \& Chow, C. W. C. (2005).Customers'adoption of banking channels in Hong Kong. The International Journal of Bank Marketing, 23(2/3), 255-272.

30. Wang, Y-S., Wang, Y-M., Lin, H-H., \& Tang, TI. (2003). "Determinants of user acceptance of Internet banking: an empirical study, Internet Research, 14(5), 501-519.

31. Wolburg, J. M. (2007). Playing the zero-sum game with diversity: who's the worthiest of them all?" The Journal of Consumer Marketing, 24(5), 261-263.

\section{TABLES}

Table 1: Research Sample Characteristics (as \% of Respondents)

Survey language

PC owner or access

Internet access at home

Internet connection type

Length of time using Internet

Frequency of using the Internet

Used Internet banking in last 12 months

Gender

Age

Marital Status

Birth Country

Primary language spoken at home

County of residence

Highest level of education

Primary school attended where

Household income

Job or profession
46.5 English; 53.5 Chinese

87

77

58 had high speed

54 over three years

58 used Internet one or more times per day

38

38 male; 62 female

$24,18-34 ; 23,35-44 ; 25,45-54 ; 28,55$ and up

71 married; 21 never married; 8 other

80 China; 11 USA; 9 other

78 Chinese; 12 English; 10 other

83 Cook; 12 DuPage; 5 other

16 less than high school; 23 high school; 17 tech school or some college; 44 college graduate or higher

20 USA only; 11 China and USA; 48 China only; 21 other

$33,0-\$ 24,999 ; 32, \$ 25,000-\$ 49,999 ; 35, \$ 50,000$ or more 29 laborer or clerk; 26.5 manager or professional; 6 student; 6 homemaker; 5 unemployed; 9 retired; 18.5 other 
Table 2: One-Way ANOVA Intent to Use by Demographic Factors

\begin{tabular}{|c|c|c|}
\hline Demographic Factors & Attributes & Mean Scores \\
\hline$\overline{\text { Age }}$ & $18-34^{\mathrm{a}}$ & $5.58^{\mathrm{d}}$ \\
\hline \multirow[t]{3}{*}{$F(3,240)=12.75 ; p<.001$} & $35-44^{\mathrm{b}}$ & $5.23^{\mathrm{d}}$ \\
\hline & $45-54^{\mathrm{c}}$ & $4.70^{\mathrm{d}}$ \\
\hline & $55+^{\mathrm{d}}$ & $3.54^{\mathrm{a}, \mathrm{b}, \mathrm{c}}$ \\
\hline Education level & Less than high school ${ }^{\mathrm{a}}$ & $3.94^{\mathrm{d}, \mathrm{e}}$ \\
\hline \multirow[t]{4}{*}{$\mathrm{F}(4,231)=6.88 ; \mathrm{p}<.001$} & High school $^{\mathrm{b}}$ & $4.02^{\mathrm{d}, \mathrm{e}}$ \\
\hline & Some college or tech school ${ }^{\mathrm{c}}$ & 4.62 \\
\hline & College graduate $^{\mathrm{d}}$ & $5.46^{\mathrm{a}, \mathrm{b}}$ \\
\hline & Post graduate degree ${ }^{\mathrm{e}}$ & $5.66^{\mathrm{a}, \mathrm{b}}$ \\
\hline Gender & Female & 5.00 \\
\hline$F(1,245)=6.84 ; p=.009$ & Male & 4.28 \\
\hline Household income & $0-\$ 24,999^{\mathrm{a}}$ & $4.33^{\mathrm{d}}$ \\
\hline \multirow[t]{3}{*}{$F(3,216)=3.45 ; p=.017$} & $\$ 25,000-\$ 49,999^{\mathrm{b}}$ & 4.77 \\
\hline & $\$ 50,000-\$ 74,999^{c}$ & 5.37 \\
\hline & $\$ 75,000$ or greater ${ }^{\mathrm{d}}$ & $5.47^{\mathrm{a}}$ \\
\hline Survey in English or Chinese & English & 5.11 \\
\hline$F(1,246)=7.78 ; p=.006$ & Chinese & 4.36 \\
\hline Country of birth & Hong Kong or USA & 5.20 \\
\hline \multirow[t]{3}{*}{$\mathrm{F}(2,245)=3.04 ; \mathrm{p}=.05$} & Mainland China or Taiwan & 4.59 \\
\hline & Other & \\
\hline & & 4.09 \\
\hline Have used Internet banking & Yes & 6.34 \\
\hline$F(1,246)=142.26 ; p<.001$ & No & 3.69 \\
\hline Own or have access to a PC & Yes & 4.99 \\
\hline$F(1,246)=31.95 ; p<.001$ & No & 2.77 \\
\hline Type of Internet access & High speed ${ }^{\mathrm{a}}$ & $5.14^{\mathrm{b}, \mathrm{c}}$ \\
\hline \multirow[t]{2}{*}{$\mathrm{F}(2,226)=26.31 ; \mathrm{p}<.001$} & Dial Up $\mathrm{p}^{\mathrm{b}}$ & $4.61^{\mathrm{a}, \mathrm{c}}$ \\
\hline & No access ${ }^{c}$ & $2.74^{\mathrm{a}, \mathrm{b}}$ \\
\hline How long using the Internet & Never used $^{\mathrm{a}}$ & $3.07^{\mathrm{b}, \mathrm{c}, \mathrm{d}}$ \\
\hline \multirow[t]{3}{*}{$\mathrm{F}(3,240)=17.23 ; \mathrm{p}<.001$} & $<1$ year $^{\mathrm{b}}$ & $4.33^{\mathrm{a}, \mathrm{d}}$ \\
\hline & 1 to 3 years $^{\mathrm{c}}$ & $4.58^{\mathrm{a}}$ \\
\hline & 3 or more years ${ }^{\mathrm{d}}$ & $5.45^{\mathrm{a}, \mathrm{b}}$ \\
\hline Where do you have Internet access & Home plus ${ }^{\mathrm{a}}$ & $5.68^{\mathrm{b}, \mathrm{c}, \mathrm{d}}$ \\
\hline \multirow[t]{3}{*}{$F(3,239)=16.24 ; p<.001$} & Home only ${ }^{\mathrm{b}}$ & $4.51^{\mathrm{a}, \mathrm{d}}$ \\
\hline & Other $^{\mathrm{c}}$ & $4.29^{\mathrm{a}}$ \\
\hline & No access ${ }^{\mathrm{d}}$ & $2.97^{\mathrm{a}, \mathrm{b}}$ \\
\hline How often do you access the Internet & Never accessed ${ }^{\mathrm{a}}$ & $3.07^{\mathrm{c}, \mathrm{d}, \mathrm{e}}$ \\
\hline \multirow[t]{4}{*}{$\mathrm{F}(4,242)=15.99 ; \mathrm{p}<.001$} & $<=$ Once a week ${ }^{\mathrm{b}}$ & $4.25^{\mathrm{e}}$ \\
\hline & $3-5$ times a week ${ }^{c}$ & $4.37^{\mathrm{a}, \mathrm{e}}$ \\
\hline & Once a day ${ }^{\mathrm{d}}$ & $4.40^{\mathrm{a}, \mathrm{e}}$ \\
\hline & $>$ Once a day ${ }^{\mathrm{e}}$ & $5.66^{\mathrm{a}, \mathrm{b}, \mathrm{c}, \mathrm{d}}$ \\
\hline
\end{tabular}

Note. The superscripts in the far right column indicate statistically significant differences between attributes from the Bonferroni procedure. 
Table 3: Correlation Analysis between Intent to Use and Attitudinal Statements Attitudinal Statement

Pearson Correlation

There are enough advantages of Internet banking for me to consider using it.

I have the opportunity to try Internet Banking

Internet banking helps me to better manage my personal finances.

Internet banking is convenient.

I feel comfortable providing personal information through Internet banking.

When I use Internet banking, my money is as safe as when I use other banking services.

I have seen how others use Internet banking.

I need to familiarize myself with Internet banking technology.

Internet banking is difficult to use.

It bothers me to use a machine for banking transactions when I could talk with a person instead.

Mistakes are more likely to occur with Internet banking than with regular banking.

I worry that Internet banking is not secure enough and I could lose money.

Mistakes with Internet banking are more difficult to get corrected than with regular banking.

I worry that Internet banking is not secure enough to protect my personal financial information.

I worry about the privacy of my information when using Internet banking.

.503

.476

.476

.406

.315

.265

.121

$-.273$

$-.114$
Table 4: Comparison of Correlation Analyses between Intent to Use and Attitudinal Statements for Chinese Version and English Version

\section{$\underline{\text { Attitudinal Statement }}$}

$\mathbf{N}$

238

Pearson Correlation

Teed to familiarize myself with Internet banking technology. Chinese

$.254^{* * *}$

When I use Internet banking, my money is as safe as when I use other banking

.142

$\underline{\text { English }}$

services.

It bothers me to use a machine for banking transactions when I could talk with a $\quad-.132$

$-.132-.426^{* * *}$ person instead.

I worry that Internet banking is not secure enough to protect my personal

$-.106$

wormation.

I have seen how others use Internet banking.

I worry about the privacy of my information when using internet banking

.099

.016

$-.149$

.085

$.414^{* * *}$

$.388^{* * *}$

$-.215^{*}$

Note. Sig. (1-tailed); * $\mathrm{p}<.05 ; * * \mathrm{p}<.01 ; * * * \mathrm{p}<.001$. 